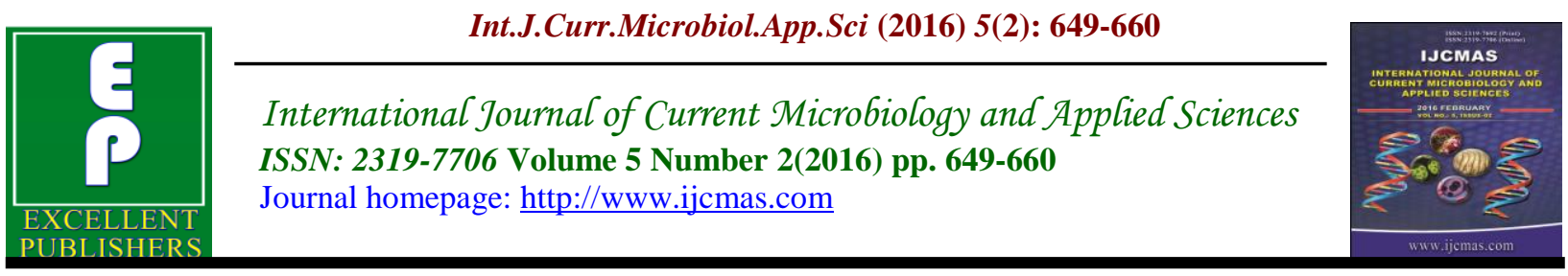

Original Research Article

doi: http://dx.doi.org/10.20546/ijcmas.2016.502.073

\title{
Peels of Selected Fruits with Antioxidant and Anthelmintic potential
}

\author{
Danamoni Sai Krishna Priya, Vaddesandhya, Buragayala Gayathri, \\ Guntupalli Gopikrishna and Varicolakaruna Sree*
}

KVSR. Siddhartha College of Pharmaceutical Sciences, Vijayawada-10, India

*Corresponding author

\begin{abstract}
A B S T R A C T
Keywords

Free radical, Anthelmintic activity, Ferric reducing power, peel extracts.

\section{Article Info}

Accepted:

29 January 2016 Available Online:

10, February 2016

Helminth infestation occurs through one or more intestinal parasitic larvae like Ascaris, whipworm, hookworm, tapeworms etc. This is a serious problem encountered in most of the developing countries, predominantly seen in tropical and subtropical zones. Morbidity and mortality rates are increasing year after year. Various extracts of the peels of Punica granatum, Musa sapientum and Maluspumila were tested for their anti oxidant and anthelmintic potential.In hydrogen peroxide method, at a conc. of $100 \mu \mathrm{g} / \mathrm{ml}$, Chloroform, methanol and aqueous extracts of apple peels produced $82.28 \%, 82.91 \%$ and $86.6 \%$; pomegranate peel extracts showed $77.51 \%, 85.97 \%$ and $75.98 \%$ and banana peel extracts produced $85.16 \%, 83.18 \%$, and $85.43 \%$ free radical scavenging activity respectively. All the extracts at a dose of $100 \mu \mathrm{g} / \mathrm{ml}$ showed significant ferric reducing power when compared to the standard ascorbic acid.In the anthelmintic activity determination, methanol extract $(40 \mathrm{mg} / \mathrm{ml})$ of banana peels showed shortest time of paralysis and death when compared to the standard albendazole. Therefore the peels of selected fruits have potential use in helminth infestations and in free radical mediated diseases.
\end{abstract}

\section{Introduction}

Helminthiasis means infection of the human body with parasitic worms such as round worms, pinworms etc. The worms usually involve the intestinal tract but sometimes they may invade other organs. It is a serious problem not only in human beings but also livestock especially in tropics (Dhar et al, 1982). The ailment is particularly predominant in developing countries in association with poor Organization performs and insufficient regulating measures.
Anaemia is a major consequence of infection with GI nematodes, they have a detrimental effect on the host's nutritional status, also cause a loss of appetite and affect the host's physical, cognitive and social development. Influx of these infections can cause morbidity, and occasionally death, by bargaining nutritional status, affecting cognitive processes, persuading tissue responses, such as granuloma, and provoking intestinal obstruction or rectal prolapse in livestock 
(Niezenet al, 1995).In a hyperinfective form the worms are concentrated in the intestinal and respiratory tracts. They also spread throughout many organs, including the central nervous system. There is increased risk of meningitis and other secondary bacterial infections making the condition more worse. Control of helminthiasis is based on drug treatment, biological control, hygiene and health education as reported by WHO. Anthelmintic herbs possess properties that destroy helminths and protozoal parasitic worms or prevent their growth or replication and can be used therapeutically in the treatment of helminthiasis. Some of the medicinal plants possessing anthelmintic activity include Hunteri aumbellata, Combretum mucronatum, Raw garlic (Allium sativum), Elaephor biadrupifera, Hillaria latifolia, citrus aromaticum, Citrus medica, Citrus aurantifolia, Diospyros mespiliformis, Cucurbita maxima, Cucurbit amoschata, Cucurbita aromatic, Hagenia abyssinicaetc.

Reactive oxygen species (ROS) have been found to playan important role in the initiation and/or progression ofvarious diseases such as atherosclerosis, inflammatory diseases, cancer and cardiovascular disease. Thus, recent studies have investigated the potentialof plant products as antioxidants against variousdiseases induced by free radicals (Pasupathi et al, 2009 and Farber, 1994). Peels of pomegranate (Punica granatum), the inedible portion contains as much as three times the total amount of polyphenols, including condensed tannins and catechins, gallocatechins and prodelphinidins. It is used in heart problems, treatment of cough and cold, used in dental hygiene, anti-aging and skin cancer (Ricci and Giamperi, 2006; Kotamballi, 2002). Peels of banana (Musasa pientum), contain protein, crude lipid, carbohydrate and crude fibre. It is used in treatment of heavy metal contamination from river water,also usedas a means of filtration for heavy metals and radionuclides occurring in water produced by the nuclear and fertilizer industries(Chang-Peng Yang et al,2001;PingyiZhang,Roy et al,2005). Apple(Maluspumila) peels are rich in Alpha-Linolenic-Acid, Asparagine, DCategin, Isoqurcetin, Hyperoside, FerulicAcid, Farnesene, Neoxathin, PhosphatidylCholine, Reynoutrin, Sinapic-Acid, CaffeicAcid, Chlorogenic-Acid, P-HydroxyBenzoic-Acid, P-Coumaric-Acid, Avicularin, Lutein, Quercitin, Rutin, Ursolic-Acid, Protocatechuic-Acid, and Silver(Edgar Pastene et al,2009; Kelly Wolfe et al, 2003).

\section{Materials and Methods}

Chloroform (Merckspecialitiespvt. Ltd.), Methanol (loba chemicals), Hydrochloric acid (Hi-pure chemicals), Sulphuric acid (Hi-pure chemicals), Ammonia ((Loba chemicals), Sodium hydroxide (SD fine chemicals), Lead acetate ( Hi-pure chemicals), Sodium nitroprusside (Lobachemicals), Acetic anhydride (Loba chemicals), Tannic acid, Molish reagent(Loba chemicals), Picric acid, Potasium hydroxide (Loba chemicals), Libbermann-Burchard's reagent, Potasium dichromate(Hi-Pure chemicals), Copper sulphate, Hydrogen peroxide, Saline solution, Ascorbic acid, DMSO(Loba chemicals), Potassium ferricyanide, Gum acacia, Sodium chloride (loba chemicals), Albendazole(local drug store).

\section{Extraction}

The fruits of Punica granatum, Malus pumila, Musa sapientum were procured from nearby fruit market and authenticated in the Department of Botany, P.B.Siddhartha College of Arts and Science, Vijayawada. The peels were manually separated and 
subjected to drying under shade and a specimen was preserved for future reference. The dried peels were made into powder in a mechanical grinder. The powdered plant material is subjected to successive extraction using different solvents like chloroform, methanol, and water. Extraction with chloroform and methanol was done by maceration. Aqueous extract is obtained using soxhlet apparatus. The following procedure was followed:

The powder is macerated with chloroform for 6 days. Then the contents are filtered by vacuum filteration. The marc is retreated with same solvent for another 3days. The contents are filtered, combined and concentrated.

The marc is dried and extracted with methanol in the same manner. After methanol extraction, the solid material was sufficiently dried and extracted with water in a soxhlet apparatus for eight hours period. The extract was concentrated. All the extracts were stored in a desiccator.

\section{Preliminary Phytochemical Screening}

The extracts obtained were weighed and yield was calculated Table1. Preliminary phytochemical screening was carried out following standard procedures (Khandelwal, 2004; Kokate,2006). The extracts were abbreviated as follows:

Chloroform extract : Punica granatum (Pomegranate) (PCE), Maluspumila (Apple) (ACE), Musa sapientum (Banana)(BCE)

Methanol extract: Punica granatum (Pomegranate) (PME), Maluspumila (Apple) (AME), Musa sapientum (Banana) (BME)

Aqueous extract : Punicagranatum (Pomegranate) (PAE), Maluspumila (Apple) (AAE), Musa sapientum (Banana) (BAE)

\section{In vitro Evaluation of Anthelmintic Activity}

Indian adult earthworms (Pheritima posthuma) were used to study anthelmintic activity due to anatomical and physiological resemblance to intestinal round worm parasites (Vidyarthi,1967;Thompson,1995). Earthworms were collected from the water logged areas and then washed with normal saline to remove soil and fecal matter. The earthworms of 5-8 cm length and $0.2-0.3 \mathrm{~cm}$ in width were used for all experimental protocols. They were authenticated in the department of Zoology, Siddhartha Arts and Science College, Vijayawada.

\section{Experimental Procedure}

Anthelmintic activity was evaluated by the method of Ajaieyoba et al (2001). Fourteen groupsof approximately equal size Indian earth worms consisting of six earthworms in each group were used for the study. Groups were treated according to the protocol.

\section{Preparation of Test Samples}

Samples for evaluation of anthelmintic activity were prepared by dissolving $2.5 \mathrm{gm}$ of crude extract in $25 \mathrm{ml}$ of $1 \%$ gum acacia solution prepared in normal saline. 20 and $40 \mathrm{mg} / \mathrm{ml} \mathrm{conc}$. were used in the study.

\section{Preparation of Standard}

A standard drug Albendazoleis procured from the nearby medical store.A solution of $50 \mathrm{mg} / \mathrm{ml}$ conc. is prepared in $1 \%$ gum acacia prepared in normal saline solution.

\section{Procedure}

The samples were taken in petriplates and adult healthy earth worms $(n=6)$ were introduced into them. Observations were 
made for the time taken to paralyze and time for death of individual worms. Paralysis was said to occur when the worms do not revive even when introduced into normal saline. Death was concluded when worms lost their motility, followed by fading away of their body colour.

\section{Evaluation of Anti-Oxidant Activity}

(a) Hydrogen Peroxide Method (Kumaran, 2007; Srinivasan,2007).

A solution of hydrogen peroxide $(20 \mathrm{mM})$ was prepared in phosphate buffer saline $(\mathrm{pH}$ 7.4), different concentrations of plant extract and standard ascorbic acid solution viz. 10, 20, 40, 60, 80 and $100 \mu \mathrm{g} / \mathrm{ml}$ in methanol (1 $\mathrm{ml}$ ) where added to hydrogen peroxide solution $(2 \mathrm{ml})$. Absorbance of hydrogen peroxide was determined at $230 \mathrm{~nm}$ after 10 min against a blank. Solution containing phosphate buffer without hydrogen peroxide is used as a blank. For each concentration, a separate blank sample was used for back ground subtraction. The antioxidant activity of the extract was expressed as IC50. All the tests were performed in triplicate and the graph was plotted with the average of three observations.

The percentage inhibition activity was calculated from $\left[\left(\mathrm{A}_{0}-\mathrm{A}_{1}\right) / \mathrm{A}_{0}\right] \times 100$, where $\mathrm{A}_{0}$ is the absorbance of the control and $\mathrm{A}_{1}$ is the absorbance of extract/standard

\section{Ferric Reducing Power Determination}

Reducing power of the extracts was determined by Yen and Chen method (Yen GC and Chen,1995). Different concentrations of fruit peel extracts and standard (STD) ascorbic acid solution viz. $20,40,60,80$ and $100 \mu \mathrm{g} / \mathrm{ml}$ in $1 \mathrm{ml}$ of methanol were mixed with phosphate buffer (2.5 ml, 0.2 M pH 6.6) and Potassium ferricyanide [ $\mathrm{K} 3 \mathrm{Fe}(\mathrm{CN}) 6](2.5 \mathrm{ml}, 1 \%)$. The mixture was incubated at $50^{\circ} \mathrm{C}$ for $20 \mathrm{~min}$. A portion $(2.5 \mathrm{ml})$ of tricholoroacetic acid $(10 \%)$ was added to the mixture, which was then centrifuged at 3,000 $\mathrm{g}(\mathrm{rpm})$ for $10 \mathrm{~min}$ atroom temperature. The upper layer of solution $(2.5 \mathrm{ml})$ was mixed with distilled water $(2.5 \mathrm{ml})$ and ferric chloride $(\mathrm{FeCl} 3)$ $(0.5 \mathrm{ml}, 0.1 \%)$. A blue-green colour was obtained in the reaction, whose O.D was measured at $700 \mathrm{~nm}$. Anincrease in the absorbance of the reaction mixture indicated increased reducing power. All the tests were performed in triplicate and the graph was plotted with the average of three observations.

\section{Results and Discussion}

Yield was calculated using formula:

$$
\% \text { Yield }=\begin{gathered}
\text { Weight of the extract } \\
\text { Weight of the plant material }
\end{gathered}
$$

The percentage yield of fruit peel extracts is given in Table1.The maximum percentage of yield was reported with methanol extract, followed by aqueous extract and chloroform extract.

\section{Preliminary Phytochemical Screening}

The chloroform extracts of all the three plants contain alkaloids, fats and fixed oils, steroids and triterpenoids, and carbohydrates. Methanol extract of pomegranate peels contains carbohydrates, glycosides, steroids and triterpenoids. Methanol extract of apple and banana peels contains carbohydrates, fats and fixed oils, glycosides, steroids and triterpenoids. Aqueous extract of pomegranate was found to contain alkaloids, glycosides, tannins and carbohydrates. Apple aqueous extract contains carbohydrates and tannins. Banana 
aqueous extract contains glycosides and carbohydrates

Basic identification of the chemical constituents of a plant drug is possible with phytochemical screening. The therapeutic activity of any plant drug resides in its phytochemicals. A knowledge of the chemical constituents helps in disclosing the pharmacological activities.

\section{Evaluation of Anthelmintic Activity}

The anthelmintic activity of selected fruit peel extracts were evaluated using Indian earthworms against the standard albendazole. The results of Anthelmintic activity are shown in Table 3. Results are expressed as an average of six observations. Among the extracts, methanol extract $(40 \mathrm{mg} / \mathrm{ml})$ of banana peels showed shortest time of paralysis and death. At the test dose of $40 \mathrm{mg} / \mathrm{ml}$, the time required to paralyze the worms was $17.5 \pm 0.09$, min. and death was recorded at $22.5 \pm 0.19 \mathrm{~min}$. whereas the time required to paralyze and kill the worms with standard (Albendazole) was $45.0 \pm$ 0.45and $55.0 \pm 0.20 \mathrm{~min}$. respectively. The activity of methanol extract was comparable to that of standard drug Albendazole with respect to time taken to paralyze and to kill the worms. All the extracts showed dose related response. Significant activity was observed with chloroform, methanol and aqueous extracts of Punica granatum, Musa sapientum, Malus pumila. The potency of the extracts was inversely proportional to the time taken for paralysis /death of the worms. The control group animals were alive up to 24hrs.

Increasing order of potency of the extracts is:

\section{$\mathrm{BME}>\mathrm{AAE}>\mathrm{AME}>\mathrm{PAE}>\mathrm{BAE}>\mathrm{PME}$}

Chemotherapeutic agents act as anthelmintics by disruption of neuromuscular physiology, blockade of energy metabolism, disrupting reproductive system which is highly efficient in these parasites(Martin,1997; Chatterjee,1967; Thor n,1977). The tested extracts may act as anthelmintics by anyone or a combination of these mechanisms. As the extracts caused paralysis as well as death, they can be confirmed to possess potent anthelmintic activity. Some synthetic phenolic anthelmintics interferes with energy of helminth parasites by uncoupling oxidative phosphorylation. Albendazole by increasing chloride ion conductance of worm muscle membrane produces hyperpolarization and reduced excitability that leads to muscle relaxation and flaccid paralysis that results in expulsion of the worms by peristalsis. The anthelmintic activity of the extract may be attributed to the presence of active components such as glycosides, triterpenoids, alkaloids, and tannins that may act by one or the other mechanisms as explained above. The anthelmintic properties of these phytoconstituents are well documented (Vigar, 1984; Bate Smith, 1962; Harekrishna, 2010; Bhakta,2013; Ajay Sharma, 2011).

\section{Evaluation of Anti-oxidant Activity}

Free radical scavenging activity of the selected extracts was carried out by $\mathrm{H}_{2} \mathrm{O}_{2}$ method. The results are displayed in Table 4 , fig $2,3 \& 4$. The scavenging activity of the standard ascorbic acid and various peel extracts after incubation for 10 minutes was observed to increase with an increase in their concentration. 
Table.1 Percentage Yield

\begin{tabular}{|c|c|c|c|}
\hline S.no & Solvent & Name of the extract & \%yield \\
\hline 1 & \multirow{3}{*}{ Chloroform } & PCE & 3 \\
\hline 2 & & $\mathrm{ACE}$ & 2 \\
\hline 3 & & $\mathrm{BCE}$ & 2.5 \\
\hline 4 & \multirow{3}{*}{ Methanol } & PME & 5 \\
\hline 5 & & AME & 3 \\
\hline 6 & & BME & 4.5 \\
\hline 7 & \multirow{3}{*}{ Aqueous } & PAE & 4 \\
\hline 8 & & AAE & 3 \\
\hline 9 & & BAE & 3.5 \\
\hline
\end{tabular}

Table.2 Preliminary Phytochemical Screening

\begin{tabular}{|l|l|c|c|c|c|c|c|c|c|c|}
\hline SL.NO & TEST & PCE & PME & PAE & ACE & AME & AAE & BCE & BME & BAE \\
\hline 1 & Test for alkaloids & + & + & + & + & + & - & + & + & - \\
\hline 2 & Test for carbohydrates & + & + & + & + & + & + & + & + & + \\
\hline 3 & Test for fats and fixed oils & + & - & - & + & + & - & + & + & - \\
\hline 4 & Test for glycosides & - & + & - & - & + & - & - & - & + \\
\hline 5 & Test for specific glycosides & - & - & + & - & - & - & - & - & - \\
\hline 6 & Test for tannins & - & - & + & - & - & + & - & - & - \\
\hline 7 & $\begin{array}{l}\text { Test for steroids and } \\
\text { triterpinoids }\end{array}$ & + & + & - & + & + & - & + & + & - \\
\hline 8 & Test for flavanoids & - & - & - & - & - & - & - & - & - \\
\hline
\end{tabular}

+ indicates presence, -indicates absence

Fig.1 Radical scavenging activity of Pomegranatepeelspeels

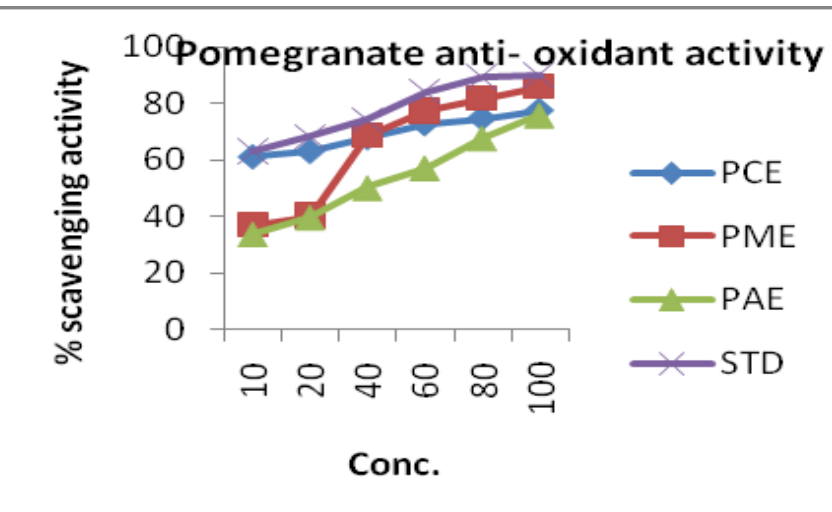


Fig.2 Radical Scavenging Activity of Apple Pomegranatepeelspeels

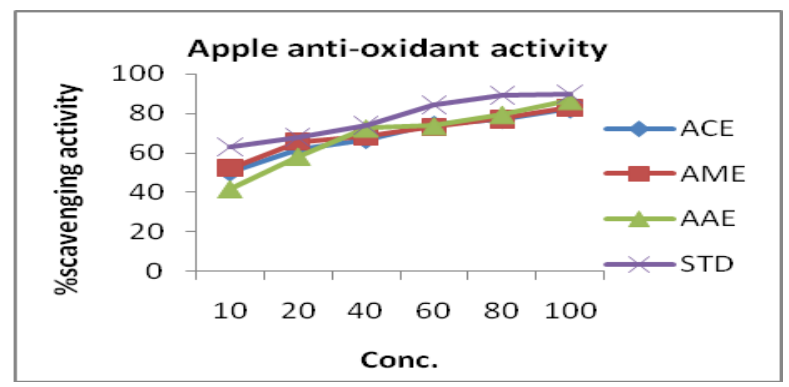

Fig.3 Radical Scavenging activity of Banana Peels

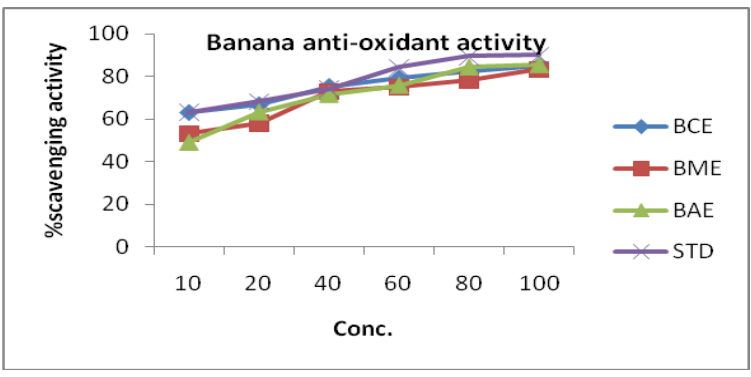

Table.3 Anthelmintic Activity

\begin{tabular}{|c|c|c|c|c|}
\hline \multirow[t]{2}{*}{ SL.NO } & \multirow[t]{2}{*}{ SAMPLE } & \multirow[t]{2}{*}{ DOSE(mg/ml) } & \multicolumn{2}{|c|}{ RESPONSE } \\
\hline & & & $\begin{array}{l}\text { Paralysis } \\
\text { Time(Min) }\end{array}$ & $\begin{array}{l}\text { Death } \\
\text { Time(Min) }\end{array}$ \\
\hline 1 & CONTROL & & $\begin{array}{l}\text { NO } \\
\text { RESPONSE }\end{array}$ & $\begin{array}{l}\text { NO } \\
\text { RESPONSE }\end{array}$ \\
\hline 2 & PME & 20 & $42.5+0.11$ & $50.5 \pm 0.3$ \\
\hline 3 & PME & 40 & $32.5 \pm 0.14$ & $44.5 \pm 0.08$ \\
\hline 4 & PAE & 20 & $49 \pm 0.16$ & $54.5 \pm 0.11$ \\
\hline 5 & PAE & 40 & $22.5 \pm 0.06$ & $29.0 \pm 0.15$ \\
\hline 6 & AME & 20 & $62.5 \pm 0.18$ & $74 \pm 0.14$ \\
\hline 7 & AME & 40 & $21.5 \pm 0.16$ & $32.5 \pm 0.07$ \\
\hline 8 & $\mathrm{AAE}$ & 20 & $90+0.09$ & $100 \pm 0.08$ \\
\hline 9 & AAE & 40 & $20 \pm 0.12$ & $35 \pm 0.18$ \\
\hline 10 & BME & 20 & $55+0.06$ & $71+0.16$ \\
\hline 11 & BME & 40 & $17.5+0.09$ & $22.5+0.19$ \\
\hline 12 & BAE & 20 & $40 \pm 0.17$ & $52.5 \pm 0.05$ \\
\hline 13 & BAE & 40 & $30+0.01$ & $40+0.14$ \\
\hline 14 & ALBENDAZOLE(STD) & 50 & $45+0.45$ & $55+0.20$ \\
\hline
\end{tabular}


Table.4 H2O2 Free Radical Scavenging Activity of Fruit Peel Extracts

\begin{tabular}{|l|l|l|l|l|l|l|l|l|l|l|}
\hline \multirow{2}{*}{$\begin{array}{l}\text { Conc } \\
(\boldsymbol{\mu g} / \mathbf{m l})\end{array}$} & PCE & PME & PAE & ACE & AME & AAE & BCE & BME & BAE & STD \\
\hline 10 & 60.97 & 36.96 & 33.86 & 50.08 & 52.24 & 41.54 & 62.94 & 53.05 & 49.01 & 63.12 \\
\hline 20 & 62.94 & 40.1 & 39.74 & 61.6 & 65.55 & 58.18 & 66.63 & 57.91 & 63.3 & 68.25 \\
\hline 40 & 67.8 & 68.7 & 50.26 & 66.72 & 68.52 & 72.57 & 75.26 & 72.75 & 71.49 & 74.19 \\
\hline 60 & 72.84 & 77.51 & 57.28 & 74.37 & 73.29 & 73.74 & 79.31 & 74.91 & 75.71 & 84.26 \\
\hline 80 & 74.73 & 81.83 & 67.8 & 76.97 & 77.24 & 79.49 & 82.55 & 77.96 & 84.26 & 89.47 \\
\hline 100 & 77.51 & 85.97 & 75.98 & 82.28 & 82.91 & 86.6 & 85.16 & 83.18 & 85.43 & 90.01 \\
\hline
\end{tabular}

Table.5 Reducing Power of Various Peel Extracts

\begin{tabular}{|c|c|c|c|c|c|c|c|c|c|c|}
\hline \multirow[b]{2}{*}{$\begin{array}{l}\text { Conc } \\
(\mu \mathrm{g} / \mathrm{ml})\end{array}$} & \multicolumn{10}{|c|}{ O.D values } \\
\hline & PCE & PME & PAE & ACE & AME & $\mathbf{A A E}$ & BCE & BME & BAE & STD \\
\hline 10 & 0.412 & 0.31 & 0.2 & 0.219 & 0.218 & 0.35 & 0.3 & 0.353 & 0.165 & 0.198 \\
\hline 20 & 0.43 & 0.335 & 0.225 & 0.238 & 0.25 & 0.364 & 0.308 & 0.36 & 0.225 & 0.242 \\
\hline 40 & 0.439 & 0.365 & 0.265 & 0.26 & 0.275 & 0.375 & 0.358 & 0.374 & 0.27 & 0.287 \\
\hline 60 & 0.505 & 0.39 & 0.283 & 0.305 & 0.283 & 0.38 & 0.37 & 0.385 & 0.358 & 0.297 \\
\hline 80 & 0.511 & 0.445 & 0.36 & 0.385 & 0.415 & 0.41 & 0.445 & 0.398 & 0.38 & 0.31 \\
\hline 100 & 0.518 & 0.512 & 0.435 & 0.425 & 0.42 & 0.425 & 0.465 & 0.435 & 0.425 & 0.362 \\
\hline
\end{tabular}

Fig.5 Pomegranate Peels Reducing Activity

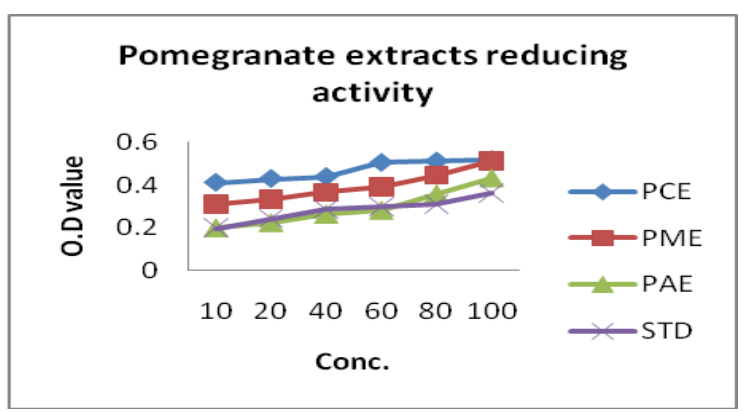

Fig.6 Apple Peels Reducing Activity

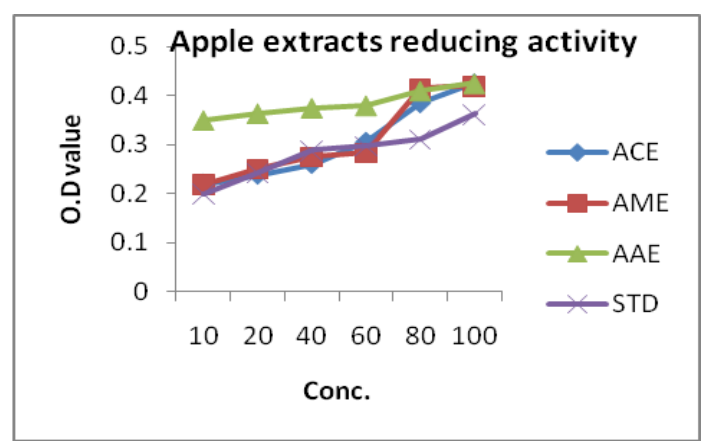


Fig.7 Banana Peels Reducing Activity

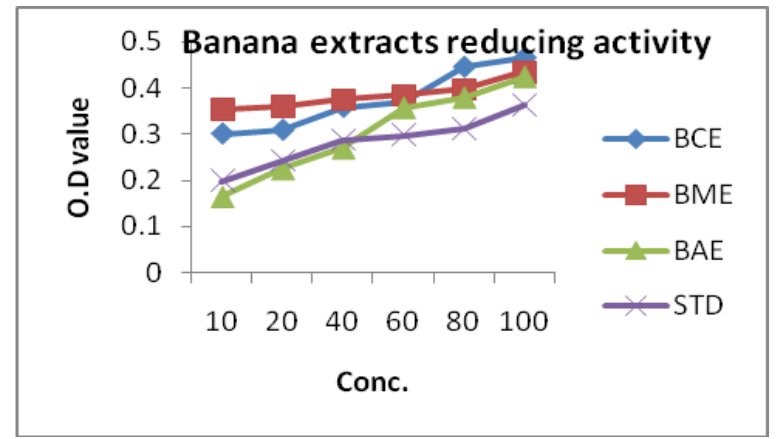

All the peel extracts exhibited significant hydrogen peroxide scavenging activity when compared to the standard ascorbic acid at similar concentrations. Among various extracts of Maluspumila, aqueous extract showed potent free radical scavenging activity which was comparable to that of the standard, ascorbic acid. Punica granatum,methanol extract and Musa sapientum aqueous extracts also showed significant activity. At $100 \mu \mathrm{g} / \mathrm{ml}$ conc. Chloroform, methanol and aqueous extracts of apple peels produced $82.28 \%$, $82.91 \%$ and $86.6 \%$; pomegranate peel extracts showed $77.51 \%, 85.97 \%$ and 75.98 $\%$ and banana peel extracts produced $85.16 \%, 83.18 \%$, and $85.43 \%$ free radical scavenging activity respectively. The $\%$ scavenging activity as exhibited by standard in this conc.was90.01.Alkaloids, tannins, steroids and triterpinoids are the chief principles identified in the tested extracts. All these extracts possessed antioxidant activities. Tannins have a strong free radical scavenging activity and antiinflammatory activity. They regulate cellular activities of inflammation related cells, macrophages, lymphocytes, Neutrophils. They also modulate metabolizing enzymes like, Phospholipase A2, CycloOxygenase (COX), Lipoxygenase (LOX) and Nitric oxide synthase (NOS) (Weisburger,1999; Nabavi,2008).
Hydrogen peroxide itself is not very reactive, it can generate the highly reactive hydroxylradical $(\mathrm{OH})$ through the Fenton reaction. Thus, the scavenging of hydrogen peroxide is an important antioxidant defense mechanism(Rice-Evans et al,1995; Nabavi et al,2009; Ying Chen et al,2014; Rajesh Mandade et al,2011;Sanchez,2006).

$\mathrm{Fe}^{2+}+\mathrm{H}_{2} \mathrm{O}_{2} \mathrm{Fe}^{3+}+\mathrm{OH}+\mathrm{OH}^{-}$

The decomposition of hydrogen peroxide to water involves the transfer of electrons as in the following reaction:

$$
\mathrm{H}_{2} \mathrm{O}_{2}+2 \mathrm{H}^{+}+2 \mathrm{e}^{-} \longrightarrow 2 \mathrm{H}_{2} \mathrm{O}
$$

Electron donating ability of the tested peels may be responsible for their free radical scavenging activity.Increasing order of the free radical scavenging activity of various extracts of the fruit peels is as follows:

\section{AAE $>$ PME $>$ BAE $>$ BCE $>$ BME $>$ AME $>\mathrm{ACE}>\mathrm{PCE}>\mathrm{PAE}$.}

The results of Ferric reducing ability of the tested extracts are shown in table5,fig 5,6\&7. Ferric reducing power determines the electron-donating capacity of an antioxidant(Kumar et al, ). The reduction of the ferric ion $\left(\mathrm{Fe}^{3+)}\right.$ to ferrous ion $\left(\mathrm{Fe}^{2+}\right)$ is measured by the intensity ofthe resultant blue-green solution which has a maximum 
absorption at $700 \mathrm{~nm}$, and an increase in absorbance is indicative of higherreducing power of the antioxidant. The reducing power of the extracts was found to increase progressively over the concentration range studied. Extract at a dose of $100 \mu \mathrm{g} / \mathrm{ml}$ showed significant ferric reducing power when compared to the standard. Chloroform extracts of all the peels exhibited potent action when compared to methanol and water extracts.

In conclusion, based on the literature survey peels of selected fruits were evaluated foranthelmintic activity and anti-oxidant activity as they were rich in important constituents. Peels, which are considered to be a waste product were experimentally proved to possess promising anthelmintic activity and antioxidantactivity.There is a lot of scope to work in this field and reveal the hidden secrets of the fruit peels. Therefore, the fruit peels of pomegranate, banana and apple can be used in the treatment of helminth infestations and in free radical mediated diseases.

\section{References}

Ajaiyeoba,EO et al., 2001. In vitro anthelmintic properties of Buchholzia coriaceae and Gynandropsis gynandra extract. Pharm Biol. 39, 217-220.

Ajay Sharma.2011.Anthelmintic activity of the leaf of Saracaindica Linn.Asian Journal of Pharmacy and Life Science. 1 (4),391-395.

Bate Smith, EC., 1962.The phenolic constituents of plants and their taxonomic significance, dicotyledons. J. Linn. Soc. Bot. 95103,58 .

Bhakta et al.,2013. In-Vitro Anthelmintic activity of Acoruscalamus Leaves. Asian J Pharm Clin Res. 6( 3),135-
137.

Chang-PengYang., Shuji Fujita., Koei Kohno., Akiko Kusubayashi., Ashrafuzzaman, MD.,andNobuyuki Hayashi.,2001.Partial Purification and Characterization of Polyphenol Oxidase from Banana (Musa sapientum L.) Peel. J. Agric. Food Chem. 49 (3), pp 1446-1449.

Chatterjee, KD.,1967.Parasitology, Protozoology and Helminthology. 6th ed. Calcutta: In Guha Ray SreeSaraswaty Press Ltd.

Dhar, DN., Sharma, RL.,Bansal,GC.,1982.Gastrointestina 1 nematodes in sheep in Kashmir. Vet. Parasitol.11: 271-277.

Edgar Pastene., HernánSpeisky., Miriam Troncoso., Julio Alarcón and Guillermo Figueroa., 2009.In Vitro Inhibitory Effect of Apple Peel Extract on the Growth of Helicobacter pylori and Respiratory Burst Induced on Human Neutrophils.J. Agric. Food Chem. 57 (17), pp 7743-7749.

Farber, JL., 1994. Mechanism of cell injury by activated oxygen species. Env Health Perspectives102: 17-24.

Harekrishna Roy et al.,2010.Preliminary phytochemical investigation and anthelmintic activity of Acanthospermumhispidum

DC.Journal of Pharmaceutical Science and

Technology.2(5).2010:217-221.

Kelly Wolfe.,Xianzhong Wu., and RuiHai Liu.,2003. Antioxidant Activity of Apple Peels. J. Agric. Food Chem. 51 (3), pp 609-614.

Khandelwal, KR.,2004.Practical

Pharmacognosy.Edn 12,

NiraliPrakashan, Pune, 149-156.

Kokate, CK., Purohit, AP., Gokhale, SB.,2006.Pharmacognosy.Edn 36, NiraliPrakashan, Pune,252. 
Kotamballi, N., ChidambaraMurthy., Guddadarangavvahally, K. Jayaprakasha., and Ravendra P. Singh.,2002.Studies on Antioxidant Activity of Pomegranate (Punicagranatum) Peel Extract Using in Vivo Models. J. Agric. Food Chem. 50, 4791-4795.

Kumar, RS., et al,2005. Antioxidant and antimicrobial activities of Bauhinia racemosa L. stem bark, Brazilian Journal of Medical and Biological Research.38,7,pp. 1015-1024.

Kumaran, A and Karunakaran,JR., 2007. Invitro antioxidant activities of methanol extracts of five Phyllanthus species from India, LWT-Food Science and Technology.40(2), pp. 344-352.

Martin, RJ.,1997. Mode of action of anthelmintic drugs. Vet J.154: 11-34.

Nabavi, SM., Ebrahimzadeh,MA.,Nabavi, SF., Hamidinia, A.,Bekhradnia,AR., 2008. Determination of antioxidant activity, Phenol and Flavonoid content of Parrotiapersica MEY, Pharmacologyonline.2,560-567.

Nabavi, SM., Ebrahimzadeh,MA.,Nabavi, SF., Bahramian, F., 2009.Invitro antioxidant activity of Phytolaccaamericanaberries.Pharma cologyonline.1, 81-88.

Niezen,JH.,Waghorn, GC., Charleston, WAG.,1995. Growth and gastrointestinal nematode parasitism in lambs grazing either Lucerne (Medicago sativa) or Sulla (Hedysarumcoronarium), which contains condensed tannins. J Agri Sci.125, 281-289.

Pasupathi, P., Bakthavathsalam, G., Saravanan, G.,and Lathas,R.,2009.Evaluation of Oxidative Stress and Antioxidant Status in Patients with Diabetes Mellitus.Journal of Applied Sciences
Research. 5,7, 770-775.

Pingyi Zhang et al.,2005. Banana starch: production, physicochemical properties, and digestibility-a review. Carbohydrate Polymers.59,4. 443-458.

Rajesh Mandade, SA.,Sreenivas, DM.,Sakarkar and Avijit Choudhury.,2011. Radical scavenging and antioxidant activity of Hibiscus rosasinensis extract. African Journal of Pharmacy and Pharmacology. 5,17, pp. 2027-2034.

Ricci, D., Giamperi, L.,2006.Antioxidant activity of Punicagranatum fruits. Fitoterapia.77,310-312.

Rice-Evans,CA., Miller, NJ., Bolwell, PG, Bramley, PM., Pridham, JB.,1995.The relative activities of plant-derived polyphenolic flavonoid. Free Radic. Res. 22, 375383.

Sanchez, J., Melchor, G.,2006. Antioxidant activity of Rhizophora mangle barks. Fitoterapia.77,181-186.

Srinivasan, $\quad$ R., Chandrasekar,MJN.,Nanjan,MJ.,Sure sh,B., 2007. Free Radical Scavenging activity of Ipomoea obscura (L.) Ker-Gawl, Journal of Natural Remedies. 7,2, pp. 184-188.

Thompson,DP., Geary, TG., 1995.The structure and function of helminth surfaces, Biochemistry and Molecular Biology of Parasites, New York, Academic Press., 203-232.

Thorn,GW., Adams, RD., Braunwald, E., Isselbacher, KJ., Petersdorf, RG., Harrison's Principles of Internal Medicine.,1977. New York: McGraw Hill Co.

Vidyarthi,RD.,1967.A Text Book of Zoology. 14th ed. New Delhi: S. Chand and Co.132.

Vigar, Z.,1984.Atlas of Medical Parasitology. 2nd ed. Singapore: 
P.G. Publishing House.

Weisburger, JH.,1999. Mechanisms of action of antioxidants as exemplified in vegetables, tomatoes and teas, Food ChemToxicol. 37, (9-10), 943 -948 .

Yen, GC and Chen, HY.,1995. Antioxidant activity of various tea extracts in relation to their anti-mutagenicity. J. Agri. Food Chem. 43,1, 27-32.

Ying Chen et al., 2014.Antioxidant activities of saponins extracted from Radix Trichosanthis: an in vivo and in vitro evaluation. BMC Complementary and Alternative Medicine, 14,86.

\section{How to cite this article:}

Danamoni Sai Krishna Priya, Vaddesandhya, Buragayala Gayathri, Guntupalli Gopikrishna and Varicolakaruna Sree. 2016. Peels of Selected Fruits with Antioxidant and Anthelmintic potential. Int.J.Curr.Microbiol.App.Sci. 5(2): 649-660. doi: http://dx.doi.org/10.20546/ijcmas.2016.502.073 